\title{
Numerical Analysis and Investigation of the Effect of Water Entrainment Intensity on the Body of Density Currents throughVarious Turbulence Models
}

\author{
Mohammad RafieRafiee \\ Associate Professor, Water Sciences and Engineering Department, college of Agriculture, \\ JahromUniversity, Jahrom, I.R. Iran. Postal code: 74137-66171. \\ Email : mrrafiee73@gmail.com \\ Mohammad hoseinMohebi \\ Msc of civil engineering, islamicazad university, sepidan branch \\ email : hmohebi2000@yahoo.com \\ Roozbeh Aghamajidi \\ professor assistant, civil department, islamicazad university, Sepidan branch \\ email : roozbeh1381@yahoo.com
}

\begin{abstract}
The density current is the current caused by imposing gravity on the density difference of two fluids. In case this current enters into another fluid with a lower density, it becomes a subsurface density current. Density currents are generally classified into two groups of permanent stable currents (such as salty density current) and unstable density currents (such as sedimentary current or turbidity currents). The occurrence of this kind of currents in reservoirs of dams leads to the transfer of sediments to the dam body which creates a hazard for the facilities and structures intended to meet the dam's objectives. One of these methods is to remove the sediments of flooding currents through dynamic density current. On the other hand, it is time-consuming and costly to make a physical model for investigating the dynamic density current. Therefore, in this research, investigating the dynamic density current was conductedthrough Flow-3d software. Given that the software has six turbulence of K-e (two-equation), Laminar, Rng, One-equation, Eddy and Prandtl models. To examine the variation of the effect of slope, discharge and concentration on the frontal speed, the body speed profile, as well as the body of water entrainment, was performed for each of the models (for a total of six models, 90 runs) of 15 tests in Flow3d software. Then, the results of the turbulence models were compared to experimental results to obtain a more accurate disturbance model. The results indicated that laminar and eddy models had the most coordination with experimental data, and the laminar disturbance model was preferable to eddy model.
\end{abstract}

Keywords: Density current, Turbulence models, Frontal speed, Body speed profile, Waterentrainment intensity on body;

\section{Introduction}

One of these methods is to remove the sediments of flooding currents through density current dynamic.

Sedimentation difficulty has always been considered as the most important factor in shortening the service life of dams and many reservoirs have been abandoned due to filling up with sediments. This problem appears to be more evident especially in the tropical and semi-arid regions due to the high discharge of the sediment current (Brunt, 2000). In the fluvial conditions, when the sediment flows with a specific mass of $\rho_{2}=\rho_{\mathrm{w}}+d_{\rho}$ into a clear water mass having $\rho_{1}=\rho_{2}$ density, a density current is happened which is called the turbidity current. In a density current that is continually fed and the density difference is due to the temperature or the presence of soluble or suspended matter, the buoyancy flux is maintained throughout the current which is referred to as conservative gravity current. Density current on a moving bed may change its submerged discharge by erosion or sedimentation, which is referred to as non-conservative gravity flow. In such currents, the rates of suspended particles create an additional parameter (Torabipudeh, 2007).

The density current has a progressive head inside a peripheral fluid. The current of the head is temporary, and its deriving force is the pressure gradient due to the difference of density between the head and the periphery fluid.

In a non-moving peripheral fluid, the static pressure is higher than the pressure in the moving density current and the generated pressure gradient causes the permeation of the periphery fluid into a density current (Kahe, 2012). 
The water entrainment intensity of density current and the peripherialstagnant fluid is shown by Ew. The mentioned intensity of the water entrainment is due to instabilities between the density current and stagnant fluid which is defined as the ratio of water entrainment rate of Wh to the average speed of the body of density current U (Turner, 1973). Several studies have been conducted in this regard.

Ellison and Turner (1959), assumed that the water entrainment rate is proportional to the speed of density current, so they have carried out researches on density currents using a physical model. In the conducted experiments, through increasing Richardson value, the rapid reduction of water entrainment intensity values has been observed. Haghi Abi (2004) provided experiments on the density current of dissolved materials (saline water) and variable slopes, and presented a relationship for the density of water entrainment.

Parker et.al (1987) conducted experiments on saline density currents. Their experiments were conducted on two slopes of 2.86 and 4.6 degrees. Kaheh (2012) conducted a research regarding an investigation of water entrainment intensity of peripheral fluid on the current body. The results indicated that the effect of roughness on the water trainment intensity of the peripheral fluid on to body current, in the high range of Richardson values and submerged current regime,was insignificant and did not follow a specific process.

Karamzadeh (2004), studied the effect of slope and density on the water trainment coefficient in an experimental flume for 15 slopes between 0.002 to 0.03 and two densities of 30 and $40 \mathrm{gr} / 1$ with salty density current. Ghamshi (1995) performed experiments regarding the salty density current on a steady base slope. Haghi Abi (2004) investigated the effect of the slope of the floor on the density current behavior and water trainment density current of salt and sediment (Coarse and fine grained).

Parker et al. (1987) also argued that againstshear velocity, the vertical distribution of suspended particles in a density current had a very small dependence on the particle rapid falling which is a criterion for sedimentary flows in open channels. Garcia (1993) and Boque et al. (2001) calculated the local Richardson value above the maximum velocity for the subcritical and supercritical current through experimental studies.

Garcia and Parker (1993) performed experiments on hydraulic jumps in density currents at the entrance of canyon to delta.They concluded that the thickness of the sediments, exactly downstream the jumping side, tended to increase. While the shear rate ratio of the bed reduced immediately after the jumping to the speed of falling paricles.

Leader et.al (2005) provided a criterion for keeping particles in the suspended state, which is defined as the ratio of maximum vertical disturbance stresses to the submergence weight of suspended load above the floor area of the unit. McCaffrey et.al (2003) examined the spatial and temporal variations of turbidity current. They kept the measuring instruments in a constant flume and changed the feeding position of the current through the flume. Choux et.al (2005) performed similar experiments with McCaffrey et al. (2003), but at an initial density of $14 \%$ (at the entrance to the flume of about 7\%) and compared the results with each other. Their results showed that the maximum height of the speed was similar to the previous one which happened at the one-third of the height of the floor. Bass et.al (2005) showed that the distribution of suspended particles was very unstable and was controlled by the ratio of the rate of falling particle to the upward components of the local turbulence velocity (which is related to the current structure). Yu et al. (2000) examined the hydraulic sediment current with fine particles in anexperimental study through a 20 meters long reservoir, having thewidth of $20 \mathrm{~cm}$, height of $60 \mathrm{~cm}$, and constant slope.Bahrami (1388) examined the changes made to the current characteristics. Laroka et.al (2008) studied the dynamic of a three-dimensional density current on smooth and rough surfaces using numerical and laboratory simulations. Accordingly, in this study, using Flow-3d software, a high density current was simulated in three slopes, three densities, and three different discharges for the six water entrainment models. According to the mentioned states, the research goals can be stated as follows:

1. Investigating the changes of velocity and height of the current head with variations of slope, discharge and density

2. Changes in the body height of the current through changing the abovementioned parameters

3. Getting the water entrainment intensity in the current body

4. For the preceding paragraphs, the results of the each of six models were compared to the laboratory data and finally, the superior turbulence model was extracted.

In the second part of the study, the Navier-Stokes equations and other related equations, as well as disturbance models in Flow-3d software were examined. In the third section, the results and discussions were studiedwhich compared the data from the software to the laboratory data.In the fourth section, conclusions, recommendations and suggestions for completing and improving the research were presented. 


\section{Materials and Methodology}

In this study, all experiments were conducted on Flow-3d software for three discharges of $0.7,1,1.3 \mathrm{l} / \mathrm{s}$, three densities of $1.010,1.015$ and $1.020 \mathrm{gr} / \mathrm{cm}^{3}$ and six models (K-e two equation, Laminar, Rng, One-equation, Turbulence and Prandtl) having zero roughness (smooth surface). Experimental data obtained from the physical model according to table 1. It should be noted that in order to provide better results, each experiment had a special name consisting of three letters $\rho, S, Q$. Q represented the discharge, S represented the density of the density current, $\rho$ represented the density of density current. Discharge, slope and the densities indicated above were respectively ascending with indexes 1,2 , and 3. For example, $\mathrm{Q}_{1} \mathrm{Q}_{2} \mathrm{Q}_{3}$ represented experiments with discharge of $0.7 \mathrm{l} / \mathrm{s}$, slope of 1 percent and density of $1.020 \mathrm{gr} / \mathrm{cm}^{3}$. To calibrate the Flow-3d mathematical model, a geometry exactly similar to the experimental flume from which actual data was extracted. It was plotted in the geometry of the software and then, for each of the six top models, 15 experiments were carried out with the same geometric and hydraulic conditions as the laboratory conditions listed in Table 1. In other words totally $90(6 \times 15=90)$ performances were made

Table1. General characteristics of experiments performed by Kaheh

\begin{tabular}{|c|c|c|c|c|c|c|c|c|c|c|}
\hline$\hat{3}$ & ]$\left._{a}^{1-} \cdot \frac{1}{9} \cdot\right]^{\prime}$ & $\begin{array}{c}\mathrm{S} \\
(\%)\end{array}$ & $\begin{array}{c}\rho_{\mathrm{t}} \\
\left(\mathrm{gr} / \mathrm{cm}^{3}\right)\end{array}$ & $\begin{array}{c}\rho_{\mathrm{a}} \\
\left(\mathrm{gr} / \mathrm{cm}^{3}\right)\end{array}$ & $\begin{array}{c}\Delta \rho \\
\left(\mathrm{gr} / \mathrm{cm}^{3}\right)\end{array}$ & $\Delta \rho / \rho_{a}$ & $\begin{array}{c}\mathrm{g}^{\prime} \\
\left(\mathrm{m} / \mathrm{s}^{2}\right)\end{array}$ & $\begin{array}{l}\mathrm{Q}_{0} \\
\mathrm{l} / \mathrm{s}\end{array}$ & $\begin{array}{c}\mathrm{q} \\
\left(\mathrm{m}^{3} / \mathrm{s} / \mathrm{m}\right)\end{array}$ & $\begin{array}{c}\mathrm{B}_{0} \\
\left(\mathrm{~m}^{3} / \mathrm{s}^{3}\right)\end{array}$ \\
\hline 1 & $\mathrm{Q}_{1} \mathrm{~S}_{1} \rho_{2}$ & 0 & $1 / 015$ & $1 / 000$ & $0 / 015$ & $0 / 015$ & $0 / 1472$ & $0 / 7$ & $0 / 00200$ & $0 / 000294$ \\
\hline 2 & $\mathrm{Q}_{2} \mathrm{~S}_{1} \rho_{1}$ & 0 & $1 / 010$ & $1 / 000$ & $0 / 010$ & $0 / 010$ & $0 / 0981$ & 1 & $0 / 00286$ & $0 / 000281$ \\
\hline 3 & $\mathrm{Q}_{2} \mathrm{~S}_{1} \rho_{2}$ & 0 & $1 / 015$ & $1 / 000$ & $0 / 015$ & $0 / 015$ & $0 / 1472$ & 1 & $0 / 00286$ & $0 / 000421$ \\
\hline 4 & $\mathrm{Q}_{2} \mathrm{~S}_{1} \rho_{3}$ & 0 & $1 / 020$ & $1 / 000$ & $0 / 020$ & $0 / 020$ & $0 / 1962$ & 1 & $0 / 00286$ & $0 / 000561$ \\
\hline 5 & $\mathrm{Q}_{3} \mathrm{~S}_{1} \rho_{2}$ & 0 & $1 / 015$ & $1 / 000$ & $0 / 015$ & $0 / 015$ & $0 / 1472$ & $1 / 3$ & $0 / 00371$ & $0 / 000546$ \\
\hline 6 & $\mathrm{Q}_{1} \mathrm{~S}_{2} \rho_{2}$ & 1 & $1 / 015$ & $1 / 000$ & $0 / 015$ & $0 / 015$ & $0 / 1472$ & $0 / 7$ & $0 / 00200$ & $0 / 000294$ \\
\hline 7 & $\mathrm{Q}_{2} \mathrm{~S}_{2} \rho_{1}$ & 1 & $1 / 010$ & $1 / 000$ & $0 / 010$ & $0 / 010$ & $0 / 0981$ & 1 & $0 / 00286$ & $0 / 000281$ \\
\hline 8 & $\mathrm{Q}_{2} \mathrm{~S}_{2} \rho_{2}$ & 1 & $1 / 015$ & $1 / 000$ & $0 / 015$ & $0 / 015$ & $0 / 1472$ & 1 & $0 / 00286$ & $0 / 000421$ \\
\hline 9 & $\mathrm{Q}_{2} \mathrm{~S}_{2} \rho_{3}$ & 1 & $1 / 020$ & $1 / 000$ & $0 / 020$ & $0 / 020$ & $0 / 1962$ & 1 & $0 / 00286$ & $0 / 000561$ \\
\hline 10 & $\mathrm{Q}_{3} \mathrm{~S}_{2} \rho_{2}$ & 1 & $1 / 015$ & $1 / 000$ & $0 / 015$ & $0 / 015$ & $0 / 1472$ & $1 / 3$ & $0 / 00371$ & $0 / 000546$ \\
\hline 11 & $\mathrm{Q}_{1} \mathrm{~S}_{3} \rho_{2}$ & $2 / 2$ & $1 / 015$ & $1 / 000$ & $0 / 015$ & $0 / 015$ & $0 / 1472$ & $0 / 7$ & $0 / 00200$ & $0 / 000294$ \\
\hline 12 & $\mathrm{Q}_{2} \mathrm{~S}_{3} \rho_{1}$ & $2 / 2$ & $1 / 010$ & $1 / 000$ & $0 / 010$ & $0 / 010$ & 0/0981 & 1 & $0 / 00286$ & $0 / 000281$ \\
\hline 13 & $\mathrm{Q}_{2} \mathrm{~S}_{3} \rho_{2}$ & $2 / 2$ & $1 / 015$ & $1 / 000$ & $0 / 015$ & $0 / 015$ & $0 / 1472$ & 1 & $0 / 00286$ & $0 / 000421$ \\
\hline 14 & $\mathrm{Q}_{2} \mathrm{~S}_{3} \rho_{3}$ & $2 / 2$ & $1 / 020$ & $1 / 000$ & $0 / 020$ & $0 / 020$ & $0 / 1962$ & 1 & $0 / 00286$ & $0 / 000561$ \\
\hline 15 & $\mathrm{Q}_{3} \mathrm{~S}$ & $2 / 2$ & $1 / 015$ & $1 / 000$ & $0 / 015$ & $0 / 015$ & $0 / 1472$ & $1 / 3$ & $0 / 00371$ & $0 / 000546$ \\
\hline
\end{tabular}

In table $1, \rho t$ and pawere the mass of the dense fluid and peripheral fluid, $\mathrm{gr} / \mathrm{cm}^{3}, \mathrm{~g}^{\prime},\left(\mathrm{g}^{\prime}=\Delta \rho / \rho \mathrm{a}^{*} \mathrm{~g}\right)$ represented the reduced acceleration gravity in terms of $Q_{o}, \mathrm{~m} / \mathrm{s}$ was the input discharge of density current in terms of $\mathrm{q}_{\mathrm{o}}, \mathrm{L} / \mathrm{S}$ represented the discharge of density current's width in terms of $\mathrm{m}^{3} /(\mathrm{s} \cdot \mathrm{m}),\left(\mathrm{q}_{\mathrm{o}}=\mathrm{Q}_{\mathrm{o}} /\left(\mathrm{b}^{*} 1000\right)=\mathrm{Q}_{\mathrm{o}} /\left(0.35^{*} 1000\right)\right)$ and $B_{o}$ was the current input immersion in terms of $\mathrm{m}^{3} / \mathrm{s}^{3}\left(B^{0}=g^{\prime *} q_{o}\right)$.

The experimental flume was used to obtain the effects of roughness and floor slope on density current. It was also utilized to invetigate the effect of variations of densities and density current discharge on these flows, having a length of 8 meters, width of $35 \mathrm{~cm}$, height of $70 \mathrm{~cm}$, and slope variation from $0 \%$ to $3 \%$. The equations used in the mathematical model of the density current included the conservation of mass principle and the amount of movement as follows.

A) The general equation of the conservation of mass:

1)

$$
V_{F} \frac{\partial \rho}{\partial t}+\frac{\partial}{\partial x}\left(\rho u A_{x}\right)+R \frac{\partial}{\partial y}\left(\rho v A_{y}\right)+\frac{\partial}{\partial z}\left(\rho w A_{z}\right)+\xi \frac{\rho u A_{x}}{x}=R D I F+R S O R
$$

$\mathrm{V}_{\mathrm{F}}$ : fluid volume, $\rho$ : fluid density and RSOR: mass source

$\mathrm{U}, \mathrm{v}$ and $\mathrm{w}$, represented velocity components in Cartesian coordinates $(\mathrm{x}, \mathrm{y}, \mathrm{z})$ or cylindrical coordinate $(\mathrm{r}, \theta, \mathrm{z})$. $A_{x}, A_{y}, A_{z}$ were areas of elements vertical to $x, y, z$ components. Coefficients of $\zeta$ and $R$, were relative to coordinate system type and in Cartesian coordinate $\mathrm{R}=1$ and $\zeta=0$. First term (RDIF) on the right side of equation of turbulence diffusion is as follows:

$$
R D I F=\frac{\partial}{\partial x}\left(v_{\rho} A_{x} \frac{\partial \rho}{\partial x}\right)+R \frac{\partial}{\partial y}\left(v_{\rho} A_{y} R \frac{\partial \rho}{\partial y}\right)+\frac{\partial}{\partial z}\left(v_{\rho} A_{z} \frac{\partial \rho}{\partial z}\right)+\xi \frac{\rho v_{\rho} A_{x}}{x}
$$


Coefficient $v_{\mathrm{p}}$ was equal to $\frac{C p \eta}{\rho}, \eta$ was the viscosity coefficient and $\mathrm{C}_{\mathrm{p}}$ represented the Schmidt value. This type of mass diffusion is related to turbulent mixing processes in non-uniform density fluids.

The fluid motion equations in three dimensions, including the Navier-Stokes equations with additional semicolons, are as follows:

3)

$$
\frac{\partial u}{\partial t}+\frac{1}{V_{F}}\left[u A_{x} \frac{\partial u}{\partial x}+v A_{y} R \frac{\partial u}{\partial y}+w A_{z} \frac{\partial u}{\partial z}\right]-\xi \frac{A_{y} v^{2}}{x V_{F}}=-\frac{1}{\rho} \frac{\partial P}{\partial x}+G_{x}+f_{x}-\frac{R S O R}{\rho V_{F}} u
$$

4)

$\frac{\partial v}{\partial t}+\frac{1}{V_{F}}\left[u A_{x} \frac{\partial v}{\partial x}+v A_{y} R \frac{\partial v}{\partial y}+w A_{z} \frac{\partial v}{\partial z}\right]-\xi \frac{A_{y} v u}{x V_{F}}=-\frac{1}{\rho}\left(R \frac{\partial P}{\partial y}\right)+G_{y}+f_{y}-\frac{R S O R}{\rho V_{F}} v$

5)

$$
\frac{\partial w}{\partial t}+\frac{1}{V_{F}}\left[u A_{x} \frac{\partial w}{\partial x}+v A_{y} R \frac{\partial w}{\partial y}+w A_{z} \frac{\partial w}{\partial z}\right]=-\frac{1}{\rho} \frac{\partial P}{\partial z}+G_{z}+f_{z}-\frac{R S O R}{\rho V_{F}} w
$$

In which $\mathrm{G}_{\mathrm{z}}, \mathrm{G}_{\mathrm{y}}, \mathrm{G}_{\mathrm{x}}$ were mass accelerations on $\mathrm{x}, \mathrm{y}, \mathrm{z}$ directions and $f_{\mathrm{z}}, f_{\mathrm{y}}, f_{\mathrm{x}}$ were viscosity accelerations on directions of $\mathrm{x}, \mathrm{y}, \mathrm{z}$ and obtained from these equations:

6)

$$
\rho V_{F} f_{x}=w s x-\left[\frac{\partial}{\partial x}\left(A_{x} \tau_{x x}\right)+R \frac{\partial}{\partial y}\left(A_{y} \tau_{x y}\right)+\frac{\partial}{\partial z}\left(A_{z} \tau_{x z}\right)+\frac{\xi}{x}\left(A_{x} \tau_{x x}-A_{y} \tau_{y y}\right)\right]
$$

7)

$$
\begin{aligned}
& \rho V_{F} f_{y}=w s y-\left[\frac{\partial}{\partial x}\left(A_{x} \tau_{x y}\right)+R \frac{\partial}{\partial y}\left(A_{y} \tau_{y y}\right)+\frac{\partial}{\partial z}\left(A_{z} \tau_{y z}\right)+\frac{\xi}{x}\left(A_{x}-A_{y} \tau_{x y}\right)\right] \\
& \rho V_{F} f_{z}=w s z-\left[\frac{\partial}{\partial x}\left(A_{x} \tau_{x z}\right)+R \frac{\partial}{\partial y}\left(A_{y} \tau_{y z}\right)+\frac{\partial}{\partial z}\left(A_{z} \tau_{z z}\right)+\frac{\xi}{x}\left(A_{x} \tau_{x z}\right)\right]
\end{aligned}
$$

8)

Shear stresses $\tau_{\mathrm{yz}}, \tau_{\mathrm{xz}}, \tau_{\mathrm{xy}}, \tau_{\mathrm{zz}}, \tau_{\mathrm{yy}}, \tau_{\mathrm{xx}}$ on above equations are obtained from these equations:

9)

$$
\tau_{x x}=-2 \mu\left[\frac{\partial u}{\partial x}-\frac{1}{3}\left(\frac{\partial u}{\partial x}+R \frac{\partial v}{\partial y}+\frac{\partial w}{\partial z}+\frac{\xi u}{x}\right)\right]
$$

10)

$$
\tau_{y y}=-2 \mu\left[\frac{\partial v}{\partial y}+\xi \frac{u}{x}-\frac{1}{3}\left(\frac{\partial u}{\partial x}+R \frac{\partial v}{\partial y}+\frac{\partial w}{\partial z}+\frac{\xi u}{x}\right)\right]
$$

11)

$$
\tau_{z z}=-2 \mu\left[\frac{\partial w}{\partial z}-\frac{1}{3}\left(\frac{\partial u}{\partial x}+R \frac{\partial v}{\partial y}+\frac{\partial w}{\partial z}+\frac{\xi u}{x}\right)\right]
$$

12)

$$
\tau_{x y}=-\mu\left[\frac{\partial v}{\partial x}+R \frac{\partial u}{\partial y}-\frac{\xi v}{x}\right]
$$

$$
\tau_{x z}=-\mu\left[\frac{\partial u}{\partial z}+\frac{\partial w}{\partial x}\right]
$$

$$
\tau_{y z}=-\mu\left[\frac{\partial v}{\partial z}+R \frac{\partial w}{\partial y}\right]
$$

\section{Body Shape}

\section{Results and Discussion}

Figure 1 shows the images of the density current body formed in the experimental model and turbulent models in the same conditions (discharge $1(1 / \mathrm{s})$, slope of $1 \%$, density of $1.015\left(\mathrm{~g} / \mathrm{cm}^{3}\right)$ ). 


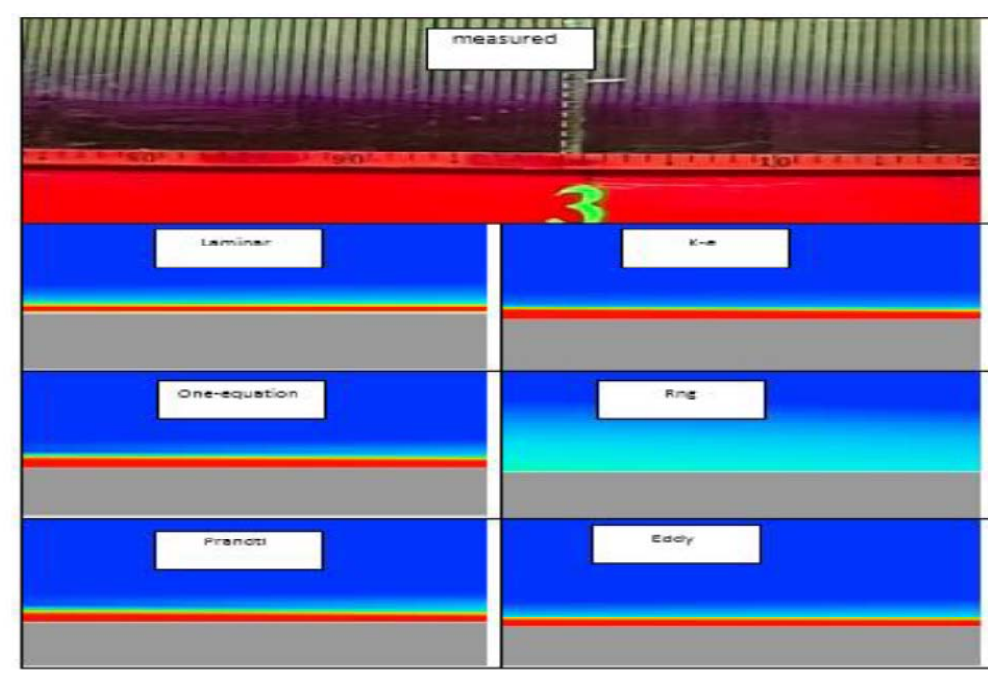

Figure 1. Comparison of body shape

\section{Body Height}

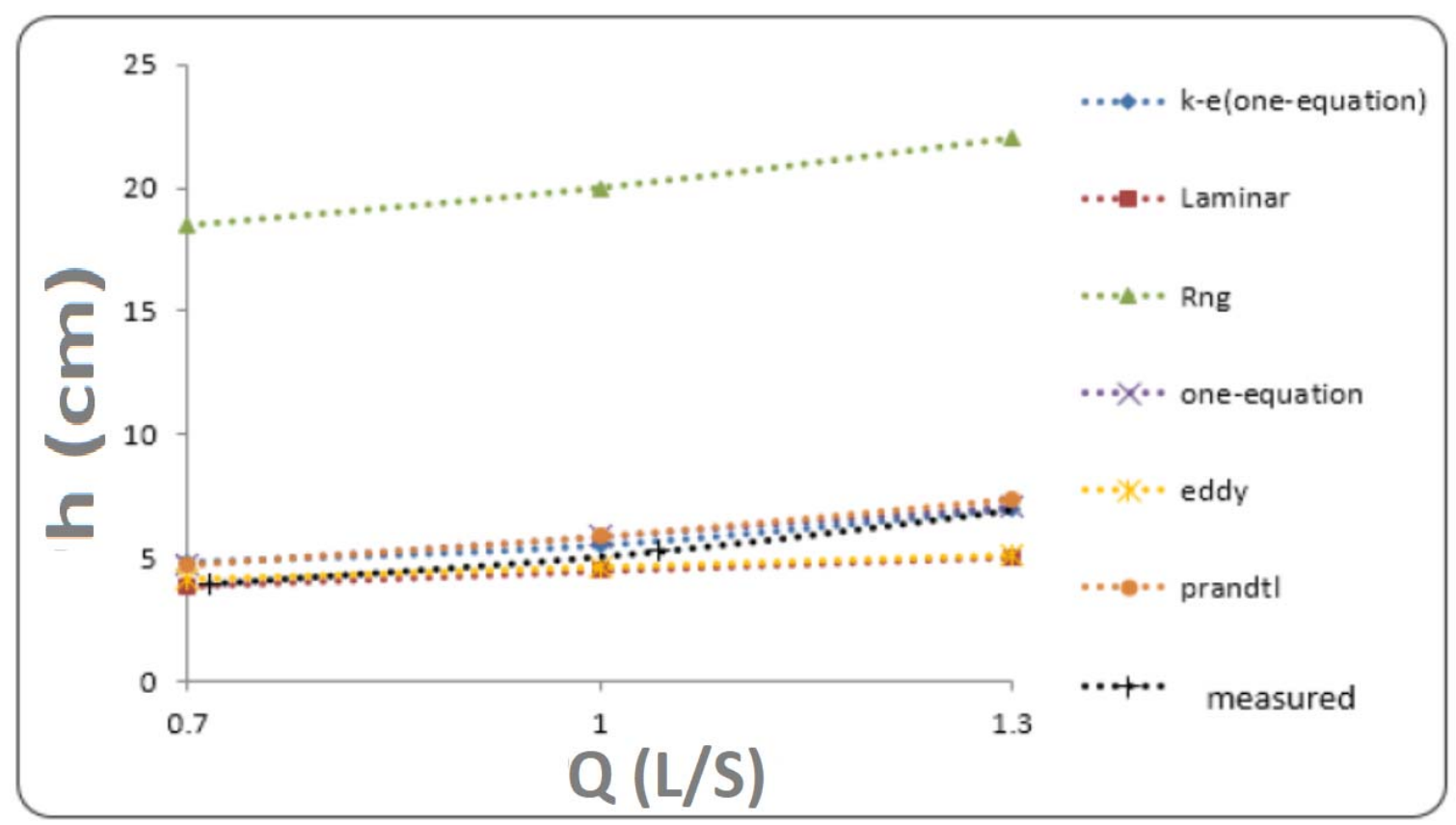

Figure 2. Body height variations versus current discharge 


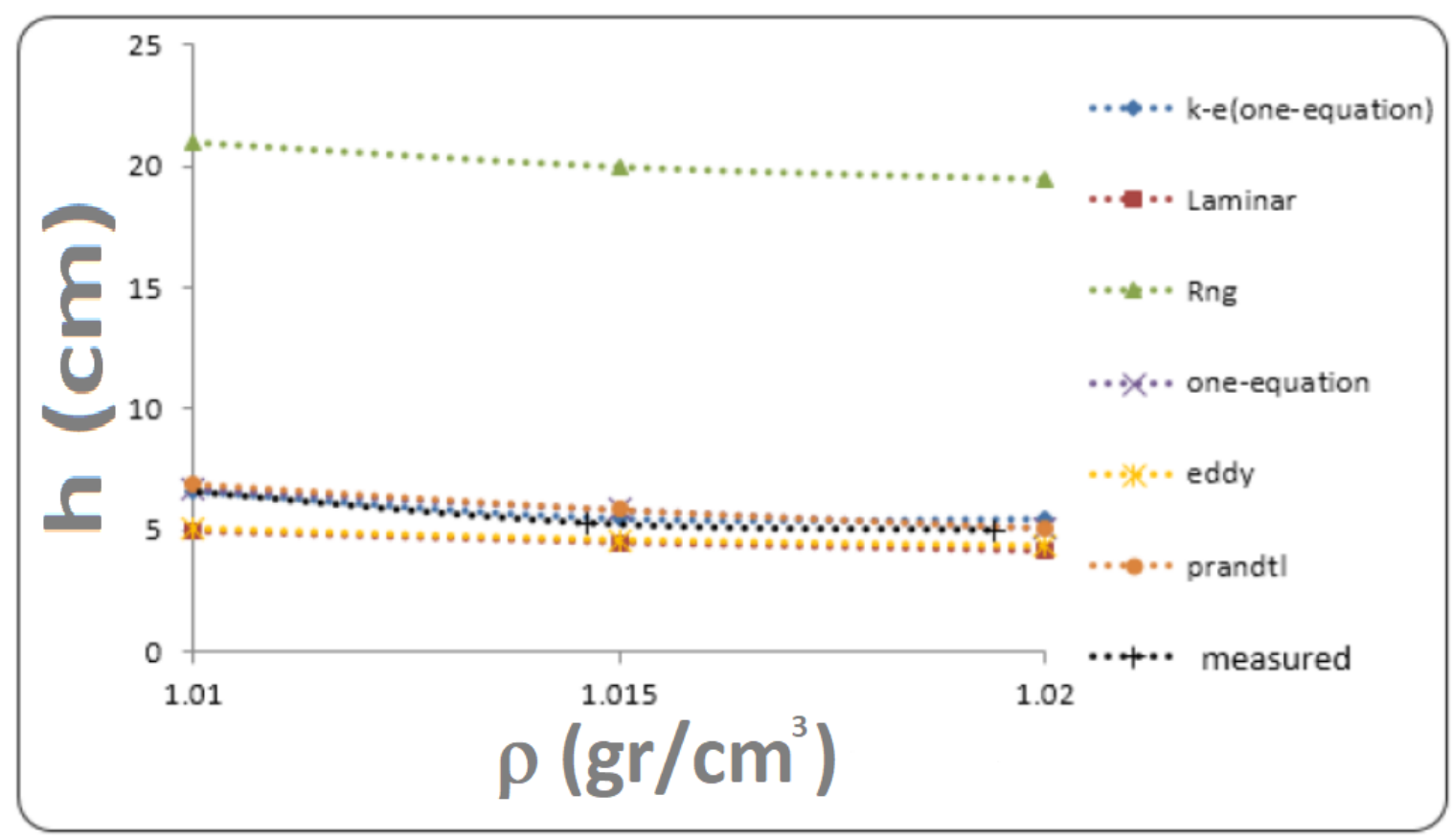

Figure 3. Body height variations versus current density

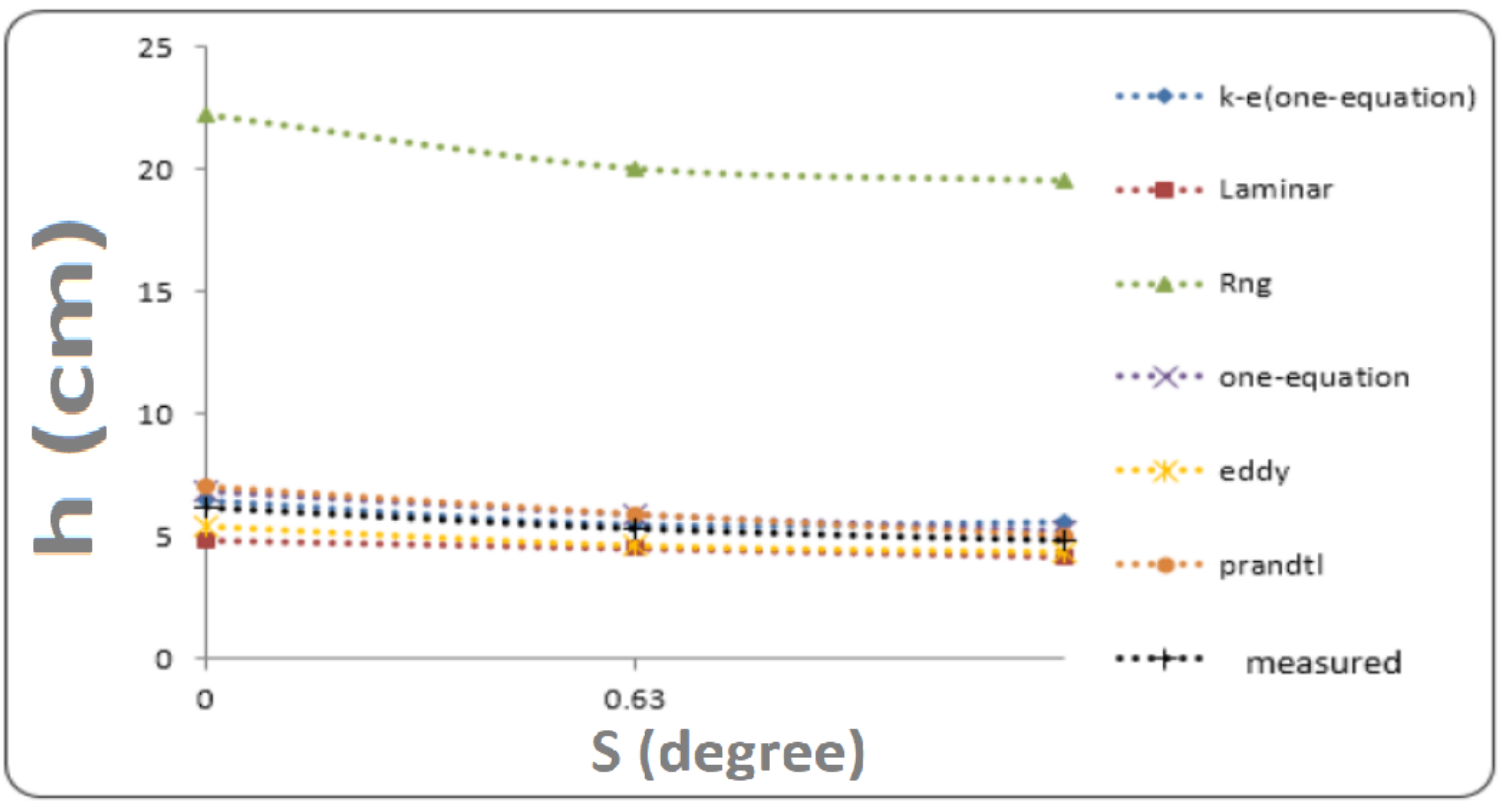

Figure 4. Body height variations versus the canal slope

Figures (2) to (4) and Table (2) are plotted for the purpose of examining and comparing the body height of a density current in various laboratory models. It can be seen from the figures that through increasing discharge rate and current density, the height of the body of the density current increased. Moreover, increasing channel slope led to its decrease. Examining the body height of the RNG numerical model, the error was very high and the other numerical models had a margin of error less than $20 \%$. 
Table 2. Error of different disturbance models compared to laboratory model for $2 / 2 \%, \mathrm{~S}=1,0$

\begin{tabular}{|c|c|c|c|c|c|c|}
\hline Models & $\begin{array}{c}\text { K-e(two- } \\
\text { equation) }\end{array}$ & Laminar & Rng & $\begin{array}{c}\text { One- } \\
\text { equation }\end{array}$ & Eddy & Prandtl \\
\hline $\begin{array}{c}\mathrm{E} \% \\
(\mathrm{~S}=0 \%)\end{array}$ & 3.19 & 22.46 & 251.26 & 4.57 & 16.44 & 9.22 \\
\hline $\begin{array}{c}\mathrm{E} \% \\
(\mathrm{~S}=1 \%)\end{array}$ & 9.22 & 19.29 & 264.64 & 8.13 & 17.36 & 6.27 \\
\hline $\begin{array}{c}\mathrm{E} \% \\
(\mathrm{~S}=2.2 \%)\end{array}$ & 13.53 & 15.82 & 309.58 & 14.86 & 12.31 & 13.73 \\
\hline$\overline{\mathrm{E}}^{\circ}$ & 8.65 & 19.19 & 275.16 & 9.186 & 15.37 & 9.74 \\
\hline
\end{tabular}

\section{Speed distribution in the body}

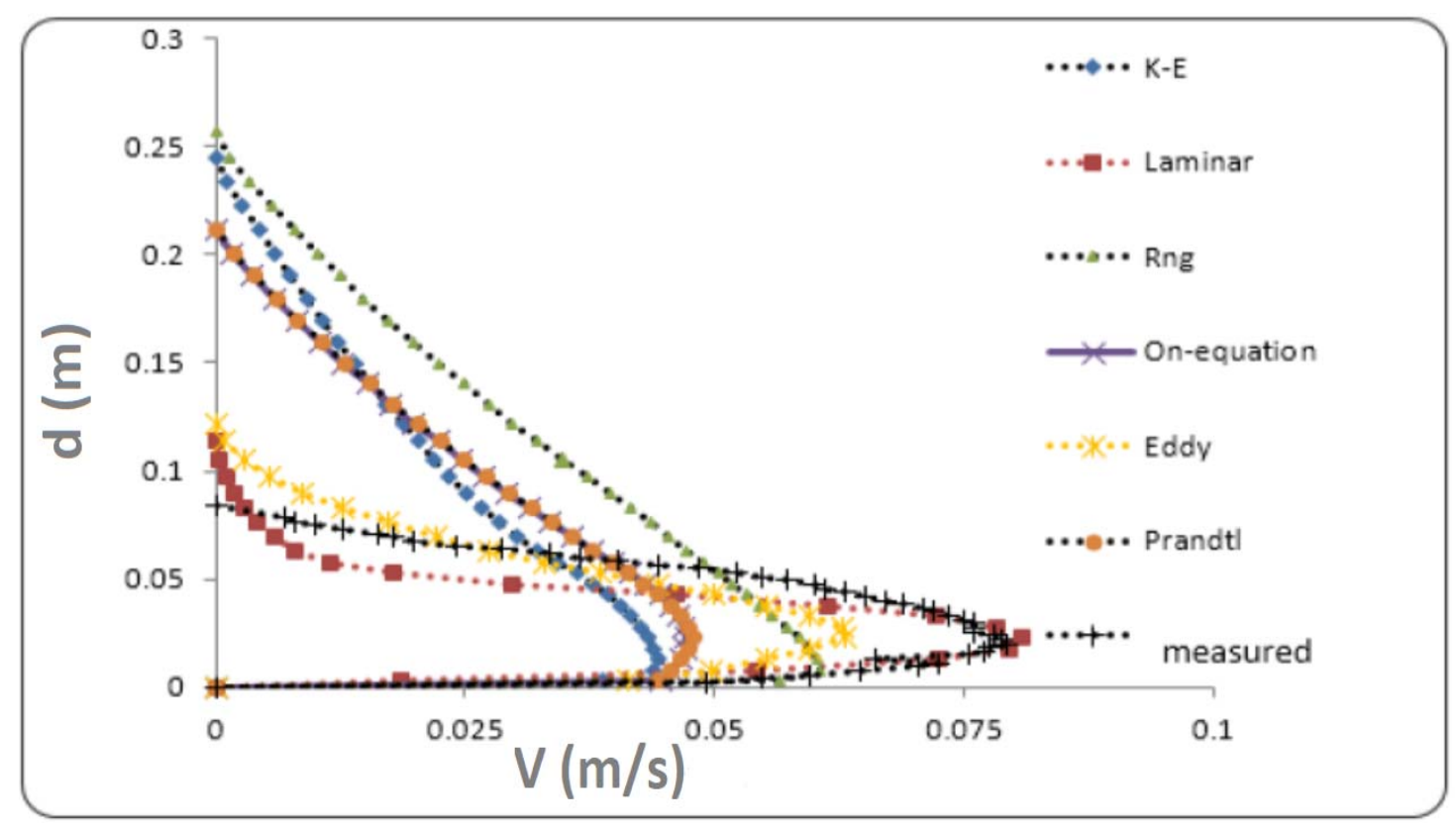

Figure 5. An example of profiles measured for different turbulence models and $\mathrm{S}=0 \%$ 


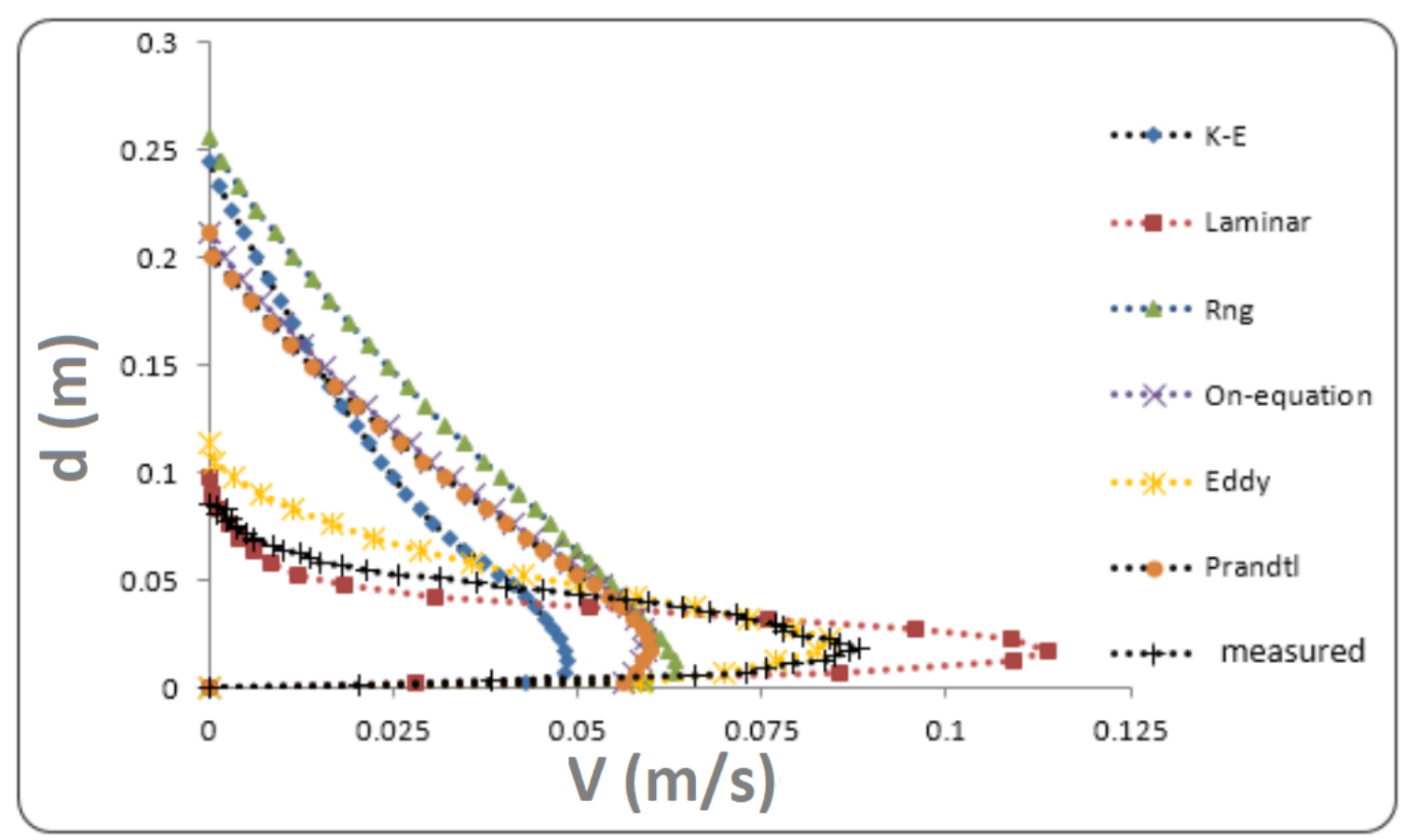

Figure 6. An example of profiles measured for different turbulence models and $\mathrm{S}=1 \%$

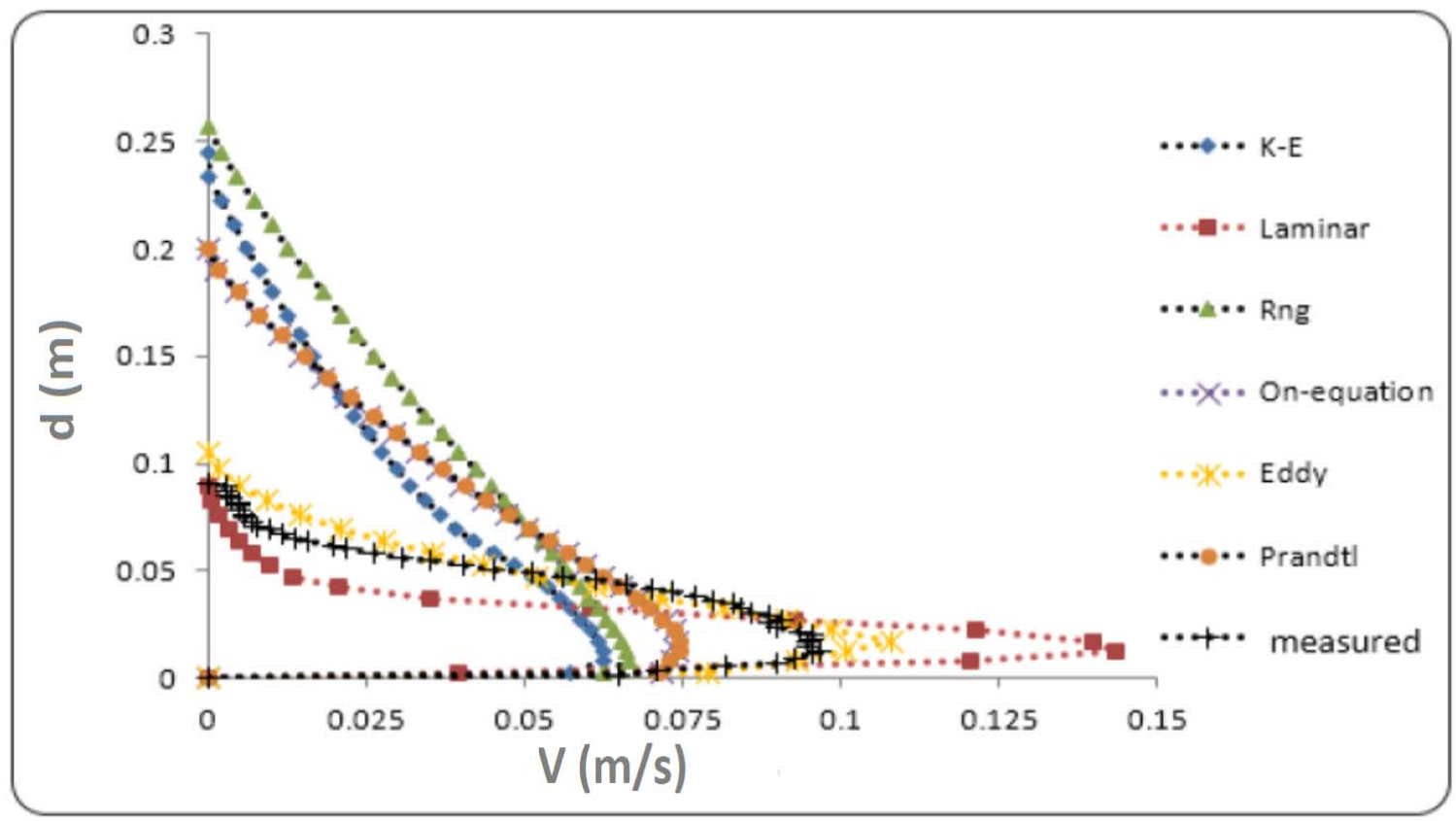

Figure 7. An example of profiles measured for different turbulence models and $\mathrm{S}=2 / 2 \%$

Figures (1) to (7) show the velocity distribution for different numerical models in different slopes. According to the shapes, it could be concluded that the body velocity profiles in the eddy and laminar turbulence models were in agreement with the experimental data.However, turbulence models of Rng, One equation, Prandtl, and K-E differed greatly with observational data.To reduce the volume of content, the models of recent turbulence were ignored and only eddy and laminar models would be discussed. It's worth noting that the two models of One_equation and Prandtlhad exactly the same profiles. 


\section{1-3 Discharge effect on body speed profile}

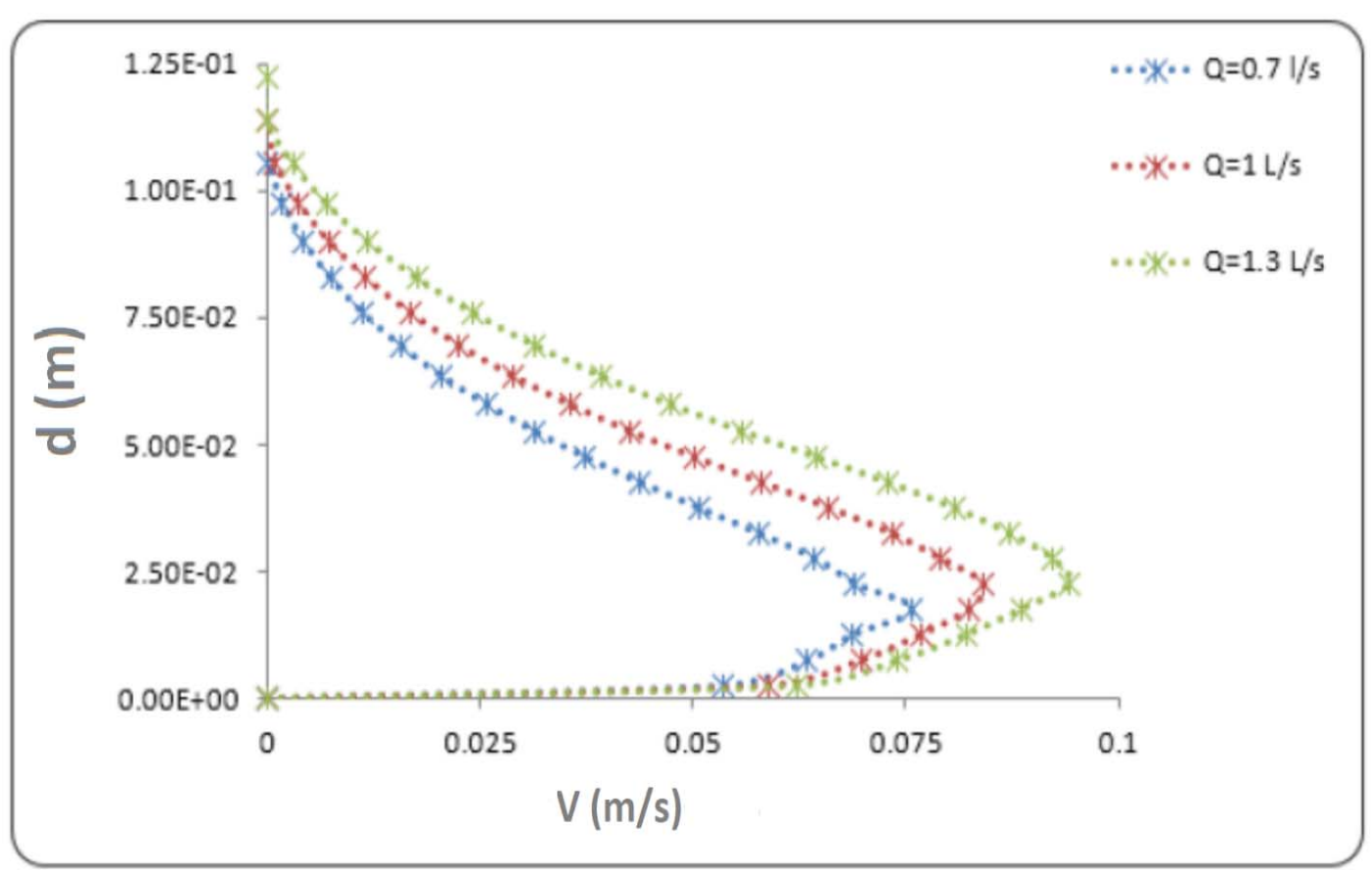

Figure 8. Speed profile variations through increasing discharge for turbulence model Eddy

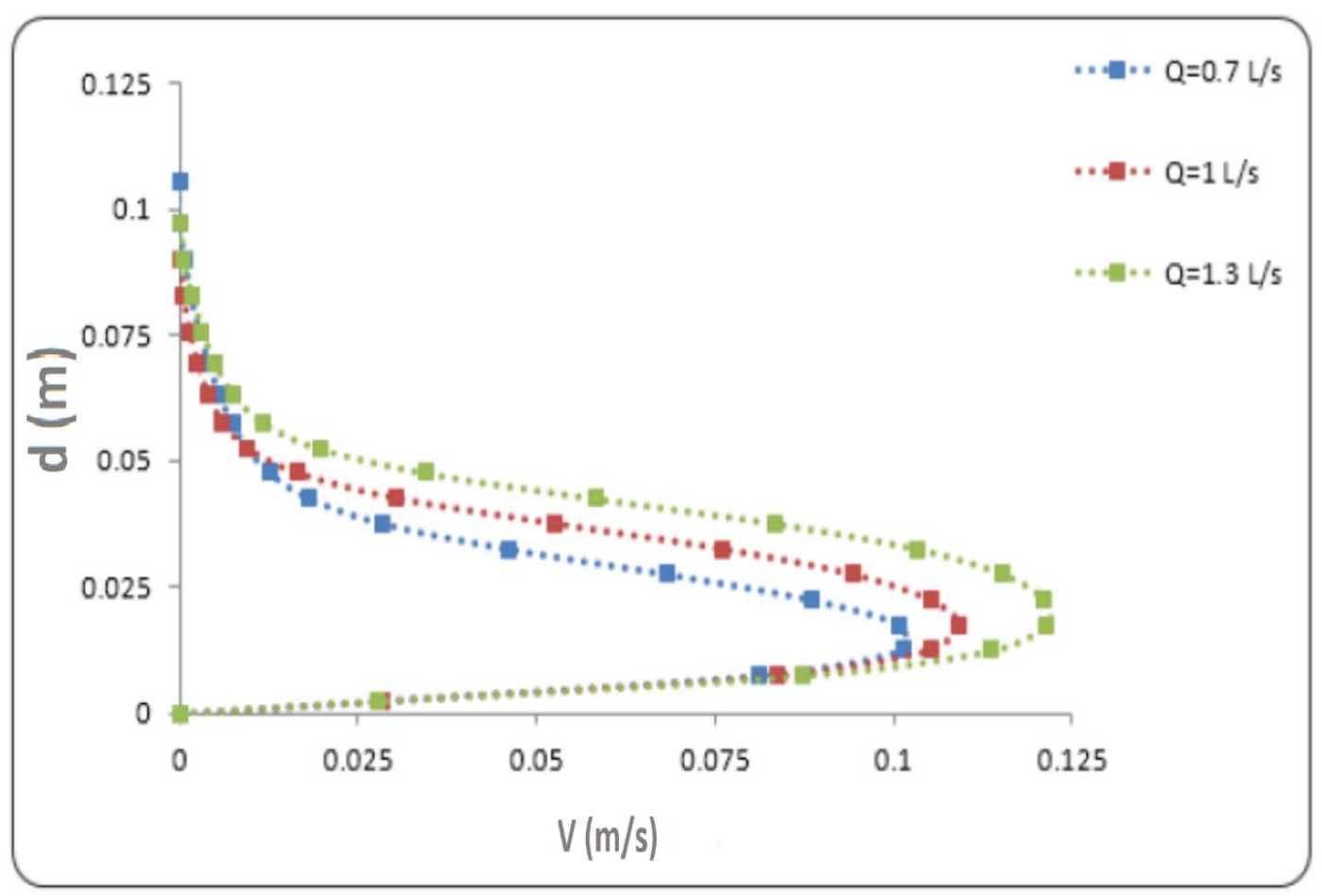

Figure 9. Speed profile variations through increasing discharge for turbulence model Laminar

In Figures (8) and (9), it is seen that in both laminar and eddy models, increasing discharge caused the velocity profile to bethicker. Additionally, it made the $U_{m}$ position to move forwards and upwards and also caused the rate of $h_{t}$ to be increased. As a result, it was in line with Mr. Kooti's result. 


\section{2-3. The effect of slope on body velocity profile}

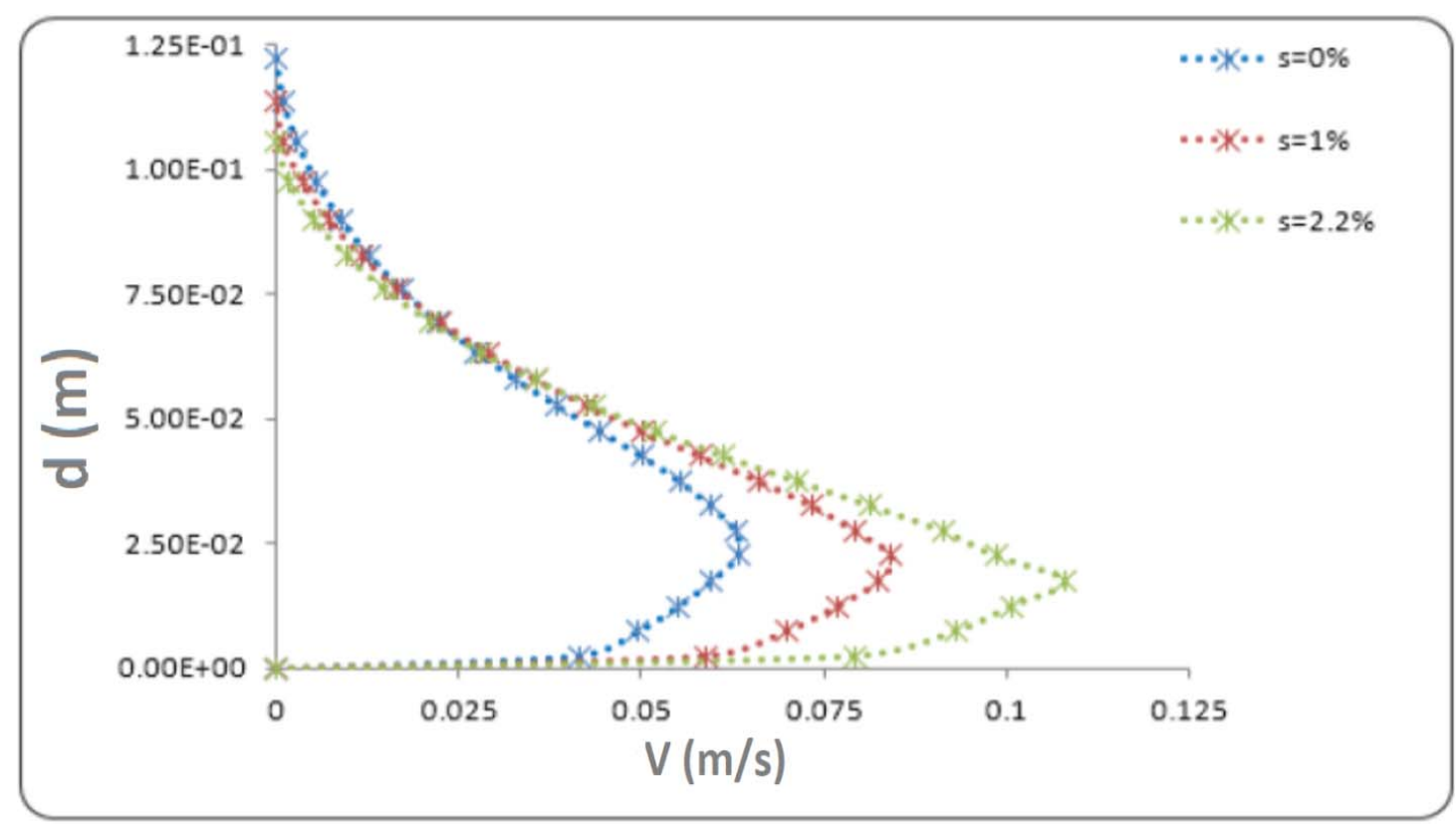

Figure 10. Velocity profile variations through increasing the slope for turbulence model of Eddy

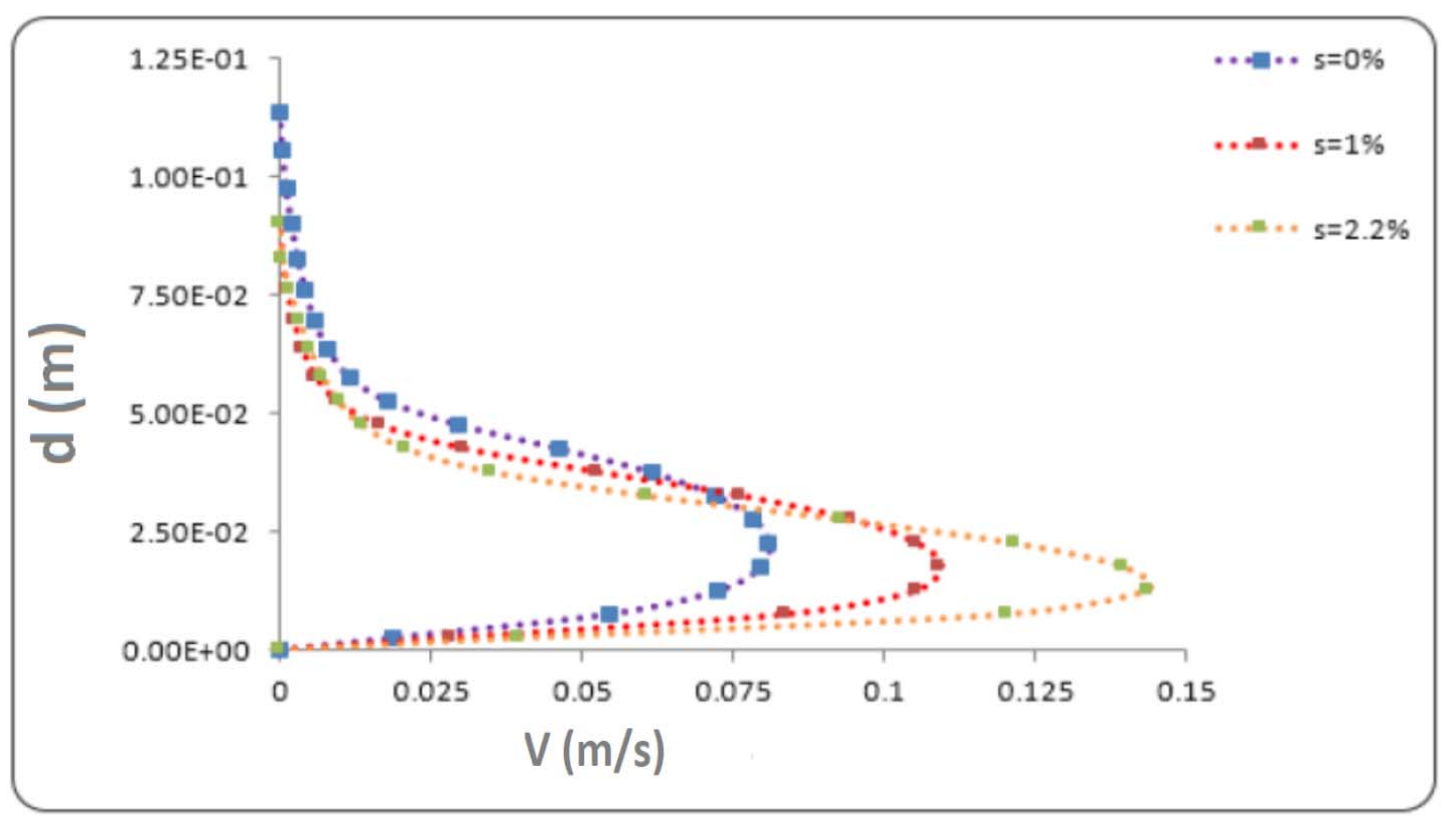

Figure 11. Velocity profile variations through increasing the slope for turbulence model of Laminar

Figures (10) and (11) showed that the effect of slope on body profiles were consistent with the abovementioned result. That is, by increasing the slope, $U_{m}$ moved forwards and downwards, and also $h_{t}$ decreased.

\section{3-3 The effect of density on the body velocity profile}

Increasing density, the maximum velocity of the forward and upward altitudes wasnot significantly altered. Also, the height of the zero point velocity was also higher at higher densities (Kootie, 1389). Figures 12 and 13 clearly show what the statement menas. 


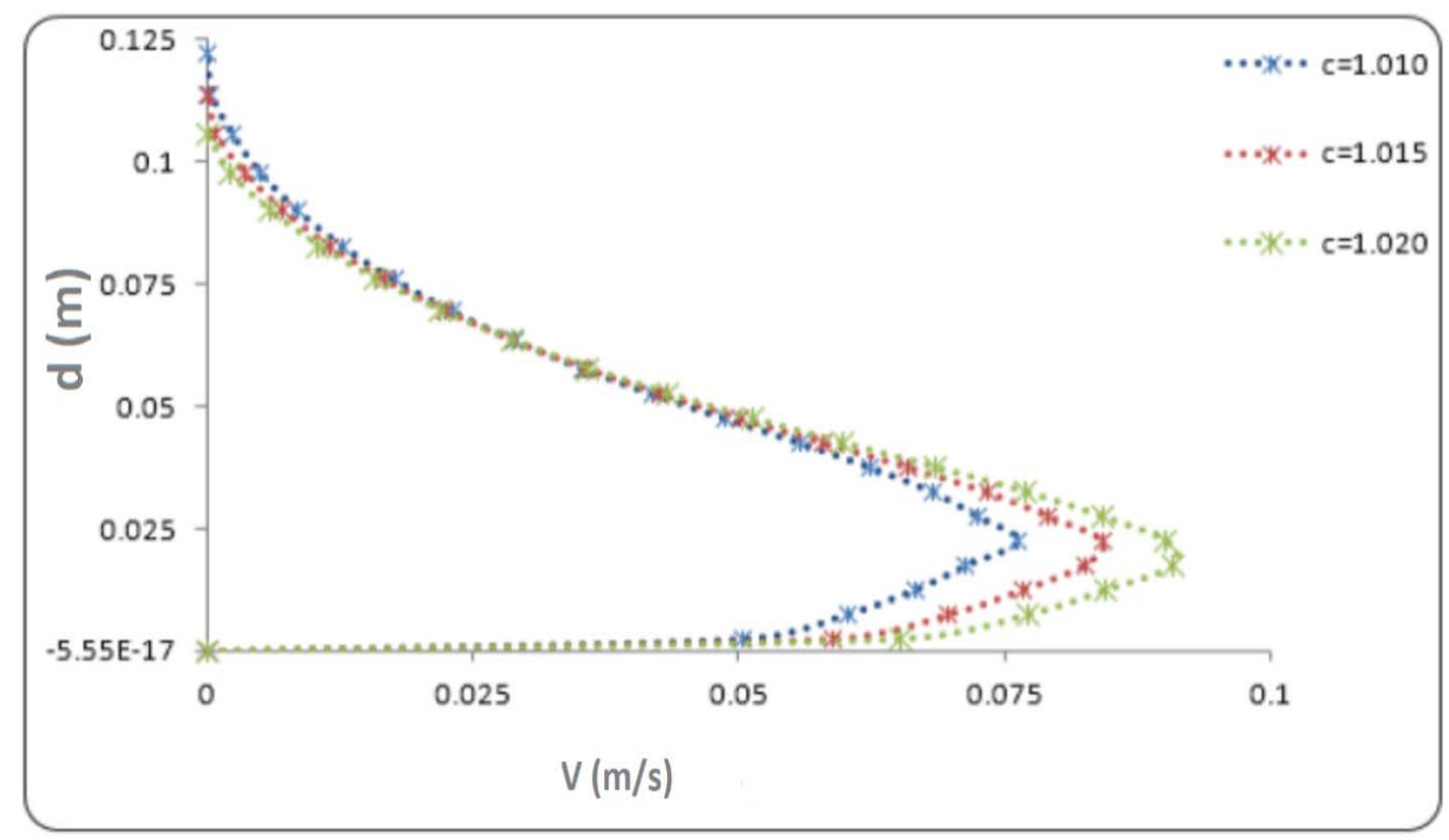

Figure 12. Velocity profile variations through increasing the density for turbulence model of Eddy

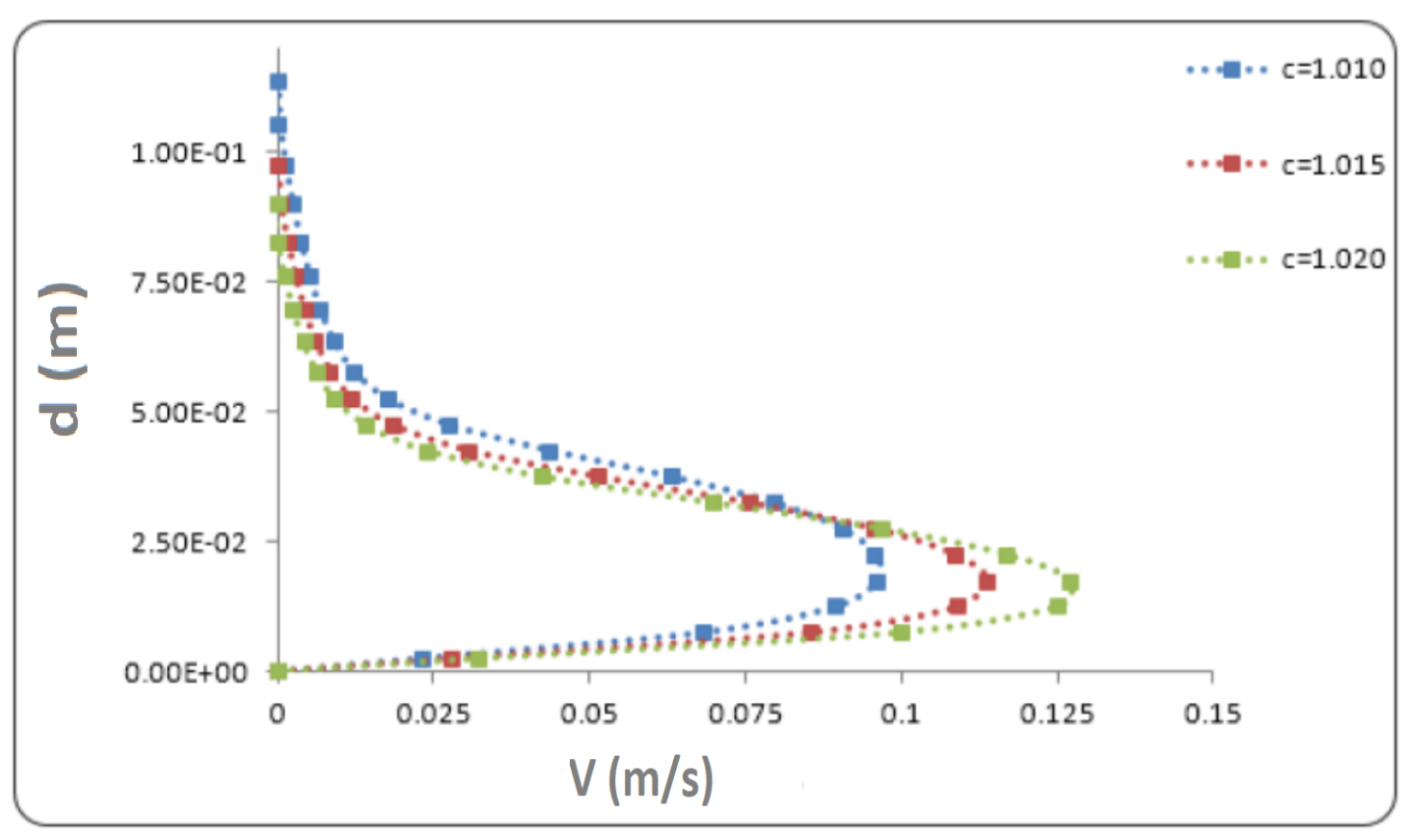

Figure 13. Velocity profile variations through increasing the density for turbulence model of Laminar

\section{3-4 Velocity distribution in the jet area and the wall of the density current body}

The velocity distribution in the jet regime can be evaluated by the following Gaussian relationship.

$$
\text { 15) } \frac{u(z)}{U_{m}}=\exp \left[-\alpha\left(\frac{z-h_{m}}{h-h_{m}}\right)^{\beta}\right]
$$

And in the wall regime, the velocity distribution is expressed through the following exponential relation.

$$
\text { 16) } \frac{u(z)}{U_{m}}=\left(\frac{z}{h_{m}}\right)^{n}
$$




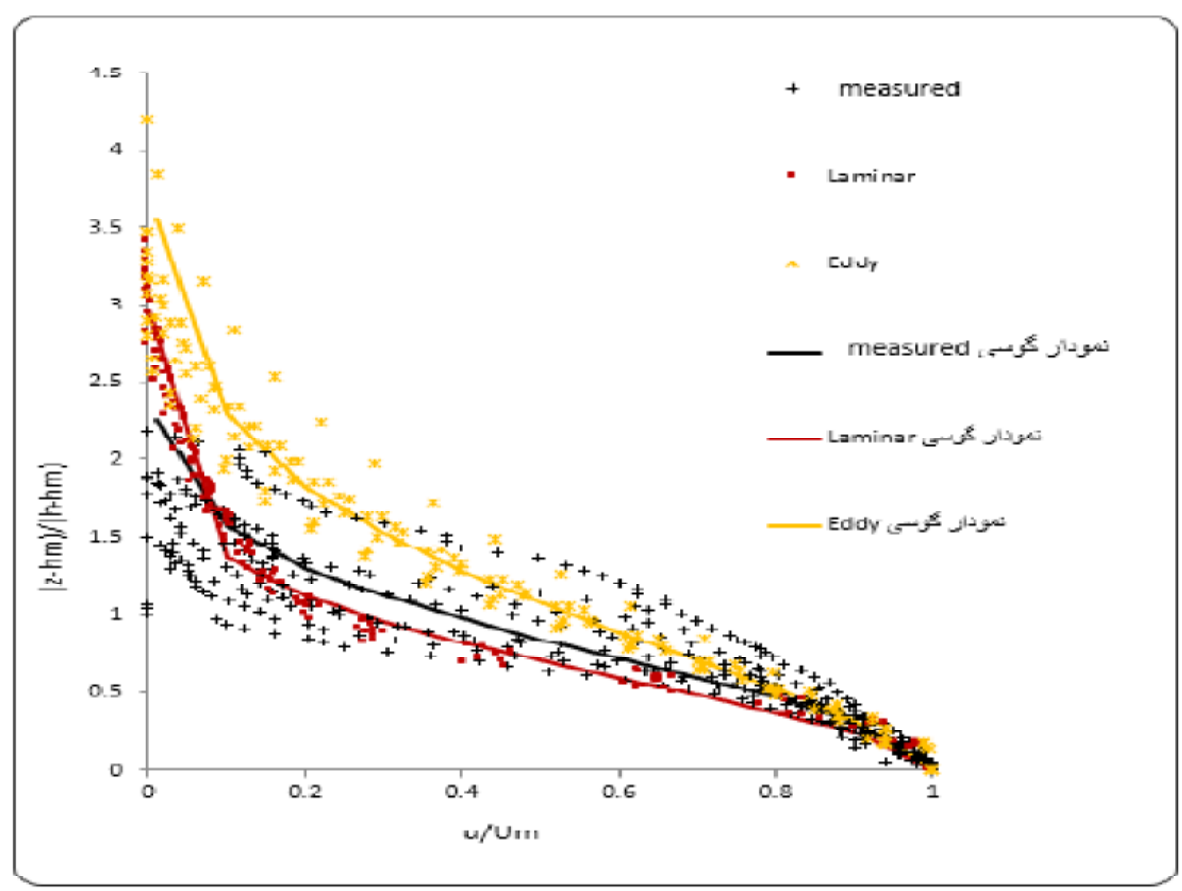

Figure 14. Dimensionless distribution of speed in the jet area

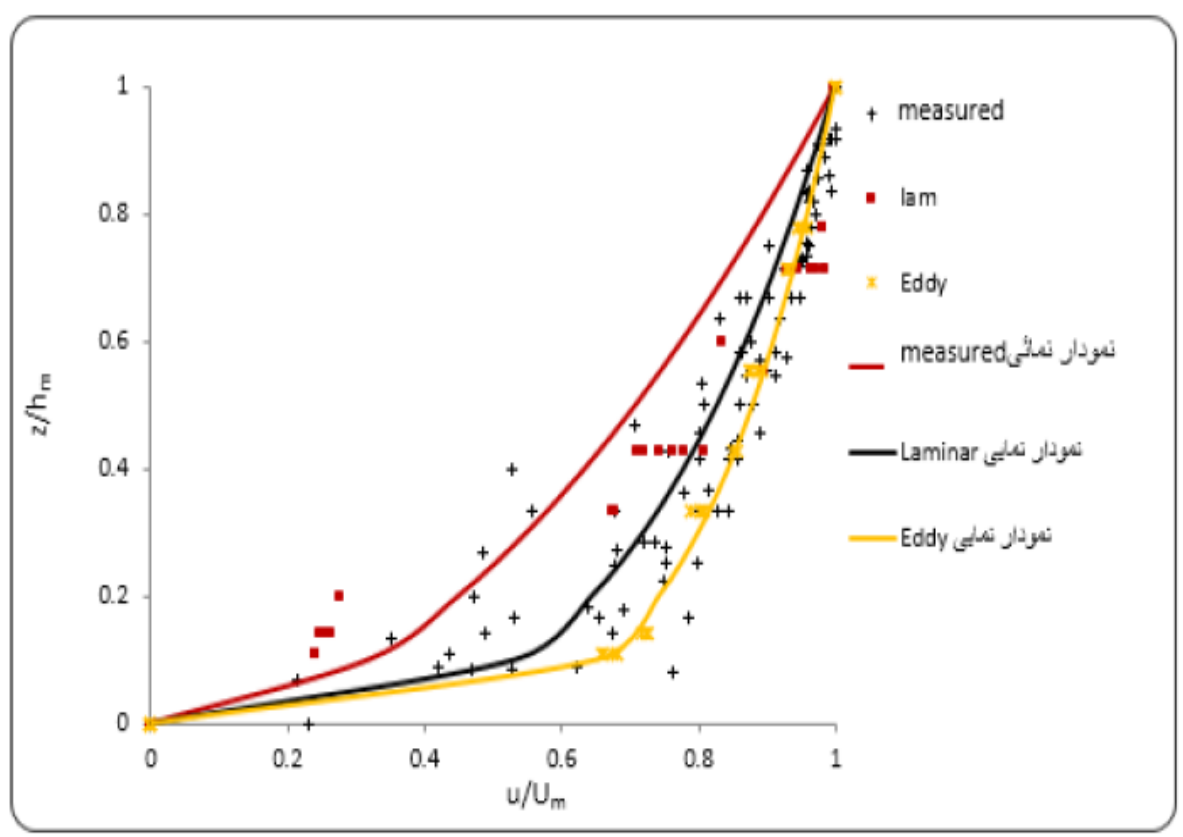

Figure 15. Dimensionless distribution of speed on the area of the wall

Figures 14 and 15 show the dimensionless speed profile in both regions. It can be concluded from the figures that in the jet area the laminar numerical model was consistent with experimental data and in the area of the wall, the Turbulence model was more accurate and the laminar model indicated satisfactory results. Given that the Turbulence model data in the jet area was higher and in the wall section was lower than the experimental data, the resultant velocity profiles were thicker and with the same reasoning, the laminar profile had a thinner profile than experimental profiles.

Using the SPSS software, the unknown coefficients of (15) and (16), $\beta, \alpha, n$, were obtained respectively,which are presented in tables 3 and 4 . The error models of laminar and eddy in estimating the velocity profile of the jet and the wall are also presented in tables (4-5) and (4-6). 
Table 3. The processed coefficients of the equation (15) for dimensionless velocity in the jet region

\begin{tabular}{|l|r|c|c|c|}
\hline \multicolumn{2}{|c|}{ profile name } & laboratory data & laminar turbulance model & eddy turbulance model \\
\hline $\begin{array}{l}\text { Guasian } \\
\text { equations } \\
\text { factors }\end{array}$ & $\alpha$ & $0 / 962$ & $1 / 312$ & $0 / 618$ \\
\cline { 2 - 5 } & $\beta$ & $1 / 924$ & $1 / 79$ & $1 / 583$ \\
\hline \multicolumn{2}{|l|}{$\begin{array}{l}\text { Regression factor } \\
\text { R2 }\end{array}$} & $0 / 93$ & $0 / 985$ & $0 / 986$ \\
\hline
\end{tabular}

Table 4. The processed coefficients of the equation (16) for dimensionless in the wall region

\begin{tabular}{|c|c|c|c|}
\hline profile name & laboraroty data & laminar model & eddy model \\
\hline $\begin{array}{l}\text { speed distribution equation } \\
\text { exponent }\end{array}$ & $0 / 273$ & $0 / 497$ & $0 / 185$ \\
\hline 2 regression coefficienct & $0 / 92$ & $0 / 95$ & $0 / 99$ \\
\hline
\end{tabular}

Table 5. Laminar and eddy disturbance Models Error Estimating Jet Velocity Profile

\begin{tabular}{|c|c|c|}
\hline Model & Laminar & Eddy \\
\hline $\mathrm{E}(\%)$ & $15 / 27$ & $26 / 16$ \\
\hline
\end{tabular}

Table 6. Laminar and eddy disturbance models in the estimation of wall velocity profile

\begin{tabular}{|c|c|c|}
\hline Model & Laminar & Eddy \\
\hline $\mathrm{E}(\%)$ & $13 / 8$ & $6 / 7$ \\
\hline
\end{tabular}

\section{Conclusion}

In the case of body height, the RNG model with $275 / 16 \%$ error had the highest difference with experimental data, and the rest of the models had a margin error of less than $20 \%$. Through increasing the density and slope, body height decreased.Increasing the body height, however, led to an increase in discharge. Laminar and eddy models in the profile of body speed had the most similar profiles with experimental data, and the following results were obtained for two jet and wall areas:

1. The dimensionless velocity profile of the jet region followed the Gaussian function. In this region, laminar model with $15 / 27 \%$ error calculated the nearest dimensionless velocity profile relative to the laboratory profiles. Turbulence model showed $26 / 16 \%$ error.

2. The dimensionless velocity profile of the wall area followed the exponential function. In this area, laminar and eddy models with $13 / 8 \%$ and $6 / 7 \%$ error had good correspondences with experimental data, respectively. In the velocity profile of the body of density current obtained from the results of laminar and eddy models such as laboratory profiles these results are highlighted:

1. As the discharge increased, the speed profiles became thicker and the maximum speed $\left(\mathrm{U}_{\mathrm{m}}\right)$ went up and down.

2. As the slope increased, the maximum speed (Um) moved forward and downward.

3. Increasing the density, the maximum velocity went forward.Although, the height changeswere not significant.

In both models of laminar and eddy disturbances, through increasing Richardson value, the intensity of water trainmentwas reduced which was consistent with experimental data and also the results of other researchers. 


\section{References}

[1] Torabipoodeh, H. (2007). The study of density current behavior in the convergences and divergences. PH.D study. ShahidChamran University. Ahvaz. Water engineering faculty.

[2] Kaheh, M. (2012). The laboratory study of density current dynamics on the coarse surfaces. PH.D. thesis. ShahidChamran University. Ahvaz. Water engineering faculty.

[3] Haghi Abi, A. (2004). The study of floor slope on the density current speed profile. PH.D thesis. ShahidChamran University. Ahvaz. Water engineering faculty.

[4] Karamzadeh, SH. (2004). The laboratory study of stagnant water stretch in density currents. M.S.c thesis. ShahidChamran University. Ahvaz. Water engineering faculty.

[5] Bahrami, H. (2009). The effect of slop failure on density current characteristics using physical model. PH.D thesis. ShahidChamran University. Ahvaz. Water engineering faculty.

[6] Brandt, S. A. (2000). "A review of resereviordesiltation". International Journal of Sediment Research, Vol. 15, pp. 321-342.

[7] Turner J. S. 1973. Buoyancy effects in fluids. Cambridge University Press, Cambridge, England.

[8] Ellison, T.H. and Turner, J.S. (1959). Turbulent Entrainment in Stratified Flow,Journal of Fluid Mechanics, Vol. 6, No. 3, pp. 423 448.

[9] Parker, G. And Toniolo, H. (2007), Note on the analysis of plunging of density flows, Journal of Hydraulic Engineering, Vol. 133, No. 6, June 2007, pp. 690-694.

[10] Ghomeshi, M. (1995). Reservoir Sedimentation Modelling. Ph.D. Thesis, University of Wollongong, Australia.

[11] Parker G., Garcia M., Fukushima Y. 1987. Experiments on turbidity currents over an erodible bed, J. Hydraul. Res,25:123-147.

[12] Garcia, M.H. (1993). Hydraulic jumps in sediment-driven bottom currents, Journal of Hydraulic Engineering, Vol. 119, No. 10, pp. 1094-1117.

[13] Buckee, C. Kneller, B. and J, Peakall. 2001. Turbulence structure in steady solute-driven gravity currents Blackwell Oxford pp, 173188.

[14] Garcia, M.H. And Parker, G. (1993), Experiments on the entrainment of sedimentinto suspension by a dense bottom current, Journal of Geophysical Research, Vol. 98, No. C3, pp. 4793-4807

[15] Leeder, M.R. Gray, T.E. And Alexander, J. (2005), Sediment suspension dynamics and a new criterion for the maintenance of turbulent suspensions. Journal of Sedimentology, Vol. 52, pp. 683-691.

[16] McCaffrey, W.D. Choux, C.M. Baas, J.H. and Haughton, P.D.W. (2003) Spatiotemporal evolution of velocity structure, concentration and grainsize stratification within experimental particulate gravity currents, Marine and Petroleum Geology 20 pp. $851-860$

[17] Baas, J.H. McCaffrey, W.D. Haughton, P.D.W. And Choux, C. (2005), Coupling between Suspended sediment distribution and turbulence structure in a laboratory turbidity current, Journal of Geophysics Research, Vol. 110, pp. 20-32.

[18] Yu, W, S. Lee, H, Y. And M, S, Hsu. 2000. Experiments on deposition behavior of fine in a reservoir. Journal of Hydraulic Engineering, 126(12): 912-920.

[19] La Rocca, M. Adduce, C., Sciortino, G. And Pinzon, A. B. (2008). Experimental and numerical simulation of three-dimensional gravity currents on smooth and rough bottom, PHYSICS OF FLUIDS, 20, 106603. 